\title{
Tratamiento de aguas residuales domesticas mediante reactor anaerobio para la reutilización del efluente en cultivos agrícolas
}

Treatment of domestic wastewater by anaerobic reactor for the reuse of effluent in agricultural crops

Tratamento de efluentes domésticos por reator anaeróbio para reaproveitamento de efluentes em lavouras agrícolas

\author{
Pedro Córdova Mendoza ${ }^{1}$ \\ pedrocordovamendoza12@gmail.com \\ https://orcid.org/0000-0003-3612-1149 \\ Isis Cristel Córdova Barrios ${ }^{2}$ \\ isiscordovabarrios@hotmail.com \\ https://orcid.org/0000-0002-3569-2671
}

\author{
Teresa Oriele Barrios Mendoza ${ }^{1}$ \\ oriele.barrios@unica.edu.pe \\ https://orcid.org/0000-0002-6466-7766
}

\author{
Raúl Antonio Navarrete Velarde ${ }^{1}$ \\ antony4569@gmail.com \\ https://orcid.org/0000-0002-8479-3866
}

${ }^{1}$ Universidad Autónoma de Ica-Facultad de Ingeniería, Ciencias y Administración, Perú

${ }^{2}$ Universidad Nacional San Luis Gonzaga-Facultad de Ingeniería Química y Petroquímica, Perú

Artículo recibido 10 de marzo 2021 / Arbitrado y aceptado 30 de marzo 2021 / Publicado 04 de mayo 2021

\section{RESUMEN}

El objetivo de la investigación fue evaluar el tratamiento de aguas residuales domesticas mediante reactor anaerobio y su influencia significativa en la reutilización del efluente en cultivos agrícolas. La investigación realizada fue de tipo experimental, nivel descriptivoexplicativo, investigación aplicada. Como resultados se obtuvo que la norma DS N003-2002-PRODUCE, establece los límites máximos permisibles y valores referenciales para la actividad en la reutilización con un $\mathrm{pH}$ entre 6-8, temperatura $<35^{\circ} \mathrm{C}$, se dispuso de la toma de muestra de la laguna de oxidación de Cachiche, como lo indica las coordenadas UTM, la biomasa anaerobia fue obtenido de Yaurilla-Parcona, se analizó el afluente tabla 5 y tabla 6, en las fechas indicadas a horas 8:00 am., (06.02.2021), y a horas 10:00 am., (02.04.2021), Discusión se evidenciaron que los resultados de caracterización ARD-010-A y ARD020-B, influenciaron en la reutilización del efluente en cultivos agrícolas. Para finalizar se tiene que la reutilización del efluente en cultivos agrícolas depende del tratamiento con reactor anaerobio en el tratamiento de aguas residuales se obtuvieron para las 32 horas con $\mathrm{pH}$ de 7.7; solidos suspendidos $38 \mathrm{mg} / \mathrm{l}$ y para los coliformes termo tolerantes un valor 890 $\mathrm{NMP} / 100 \mathrm{ml}$; valores que se encuentran por debajo de los estándares de calidad ambiental ECA AGUA para su reusó en la Categoría 3: Riego de vegetales y bebida de animales del DECRETO SUPREMO $\mathrm{N}^{\circ}$ 004-2017-MINAM.

Palabras clave: Anaerobio; agua residual domestica; reactor; remoción; carga contaminante
ABSTRACT

The objective of the research was to evaluate the treatment of domestic wastewater by means of an anaerobic reactor and its significant influence on the reuse of the effluent in agricultural crops. The research was of experimental type, descriptive-explanatory level, applied research. As results it was obtained that the norm DS N003-2002-PRODUCE, establishes the maximum permissible limits and referential values for the activity in the reuse with a $\mathrm{pH}$ between $6-8$, temperature $<35^{\circ} \mathrm{C}$, the sampling of the oxidation lagoon of Cachiche was available, as indicated by the UTM coordinates, the anaerobic biomass was obtained from Yaurilla-Parcona, the affluent was analyzed table 5 and table 6 , on the dates indicated at 8:00 am. hours, (06.02.2021), and at 10:00 a.m. (02.04.2021), Discussion showed that the characterization results ARD010-A and ARD-020-B, influenced the reuse of effluent in agricultural crops. To conclude we have that the reuse of effluent in agricultural crops depends on the treatment with anaerobic reactor in the wastewater treatment were obtained for the 32 hours with $\mathrm{pH}$ of 7.7 ; suspended solids $38 \mathrm{mg} / \mathrm{l}$ and for thermotolerant coliforms a value $890 \mathrm{NMP} / 100 \mathrm{ml}$; values that are below the environmental quality standards ECA WATER for reuse in Category 3: Irrigation of vegetables and animal drinking of the SUPREME DECREE No 004-2017-MINAM.

Key words: Anaerobic; domestic wastewater; reactor; removal; pollutant load

\section{RESUMO}

O objectivo da investigação era avaliar o tratamento de águas residuais domésticas por um reactor anaeróbico e a sua influência significativa na reutilização de efluentes em culturas agrícolas. A investigação foi experimental, descritivaexplicativa, investigação aplicada. Como resultado foi obtido que a norma DS N003-2002-PRODUCE, estabelece os limites máximos permitidos e valores referenciais para a actividade na reutilização com um $\mathrm{pH}$ entre $6-8$, temperatura $<35^{\circ} \mathrm{C}$, a amostra foi retirada da lagoa de oxidação de Cachiche, como indicado pelas coordenadas UTM, a biomassa anaeróbica foi obtida de Yaurilla-Parcona, o afluente foi analisado na tabela 5 e tabela 6 , nas datas indicadas às 8:00 horas da manhã, (06.02.2021), e às 10:00 da manhã (02.04.2021), a discussão mostrou que os resultados da caracterização ARD-010-A e ARD-020-B, influenciaram a reutilização dos efluentes nas culturas agrícolas. Finalmente, a reutilização de efluentes em culturas agrícolas depende do tratamento com um reactor anaeróbico no tratamento de águas residuais foi obtido durante as 32 horas com $\mathrm{pH}$ de 7,7 ; sólidos em suspensão $38 \mathrm{mg} / \mathrm{l}$ e para coliformes termotolerantes um valor de $890 \mathrm{NMP} / 100 \mathrm{ml}$; valores que estão abaixo das normas de qualidade ambiental ECA ÁGUA para reutilização na Categoria 3: Irrigação de vegetais e consumo animal do DECRETO SUPREME $N^{\circ}$ 004-2017-MINAM.

Palavras-chave: Anaeróbio; águas residuais domésticas; reactor; remoção; carga poluente 


\section{INTRODUCCIÓN}

Actualmente la sociedad se encuentra viviendo la crisis más grande de todos los tiempos debido a la contaminación tanto en aire, suelo y agua. El agua residual se puede definir como la combinación de los residuos líquidos o aguas portadoras de residuos procedentes, tanto de residencias como instituciones públicas, plantas industriales y comerciales. La acumulación y estancamiento de aguas residuales, la descomposición de materia orgánica que contiene puede conducir a la generación de grandes cantidades de gases malolientes. A este hecho debe añadirse la frecuente presencia de numerosos microorganismos patogénicos presentes y causantes de enfermedades de salud pública por causas de contaminación cruzada de los recursos hídricos. Estos cuerpos de agua residual pueden contener componentes que actúan como nutrientes $\mathrm{y} / \mathrm{o}$ compuestos químicos que son altamente contaminantes para un determinado ecosistema (1). Según su origen, las aguas residuales pueden clasificarse en: domesticas o urbanas, industriales, agropecuarias, de origen incontrolado (vertidos ilegales, infiltraciones) y pluviales. Sin embargo, basado en los objetivos de esta propuesta para este estudio, al hablar de aguas residuales municipales es mencionar a las aguas de origen doméstico, con alguna posible aportación de caudales pluviales y/o de procedencia incontrolada (2).

Los parámetros más utilizados para evaluar el comportamiento de las aguas residuales domesticas son la demanda química de oxigeno (DQO), que caracteriza la carga orgánica y la cantidad de oxigeno consumido en la oxidación química de la materia orgánica, el número de coliformes totales (CT), Coliformes fecales (CF) que indica el grado de contaminación patogénica y el número de bacterias saprofitas (BS), que indica la cantidad de microorganismos transformadores de materia en componentes más simples (3). En Perú, el mayor número de empresas prestadoras de servicios de agua potable y alcantarillado EPS saneamiento que se han interesado en dar tratamiento optimo a sus líquidos residuales generados, emplean el tratamiento por lagunaje como son las pozas de estabilización, sin mantenimiento, ni monitoreo alguno, por lo que son completamente ineficientes, generando problemas de deterioro ambiental y riesgo a la salud pública (1).

Por ello, el tratamiento de las aguas residuales es una obligación inaplazable para todos los países latinoamericanos. Sin embargo, dadas las limitaciones económicas de la región es necesario buscar alternativas tecnológicas que garanticen efectividad, sencillez y bajo costo lo cual permitirá revertir la contaminación por vertimiento de aguas residuales domésticas. Para el efecto es importante aprovechar todas aquellas experiencias de los países tales como: Colombia, México, Cuba, Brasil, entre otros.

\section{Tratamiento secundario-proceso biológico.} Se utilizan para convertir la materia orgánica que se encuentra finamente dividida y disuelta en el agua residual en sólidos sedimentables floculantes que puedan separarseen tanques de sedimentación (4). En un tratamiento biológico, las bacterias activas y otros microorganismos destruyen y metabolizan las materias 
orgánicas solubles y coloidales, reduciendo la DBO y la DQO a valores inferiores a $100 \mathrm{mg} / \mathrm{l}$. La velocidad de degradación depende de que se hallen presentes los microorganismos adecuados (5).

Procesos de oxidación biológica. La oxidación biológica es el mecanismo mediante el cual los microorganismos degradan la materia orgánica contaminante del agua residual. De esta forma, estos microorganismos se alimentan de dicha materia orgánica en presencia de oxígeno y nutrientes, de acuerdo con la siguiente reacción: Materia orgánica + Microorganismos + Nutrientes $+\mathrm{O}_{2} \rightarrow$ Productos Finales + Nuevos microorganismos + Energía

Tratamiento aerobio. La biomasa está constituida por microorganismos aerobios o facultativos, consumidores de oxígeno. El carbono de la materia orgánica disuelta en el agua se convierte parcialmente en $\mathrm{CO}_{2}$, con producción de energía (6).

Demanda bioquímica de oxígeno. Es la cantidad de oxígeno requerido por las bacterias para descomponer la materia orgánica en condiciones aerobias. Puede considerarse como un procedimiento en el cual los organismos vivos sirven como medio para la oxidación de la materia orgánica hasta dióxido de carbono y agua. El análisis se realizó a $20^{\circ} \mathrm{C}$ y durante cinco días, por esto se denomina: $\mathrm{DBO}_{5^{\prime}}(7)$.

Demanda química de oxígeno: $L a$ DQO mide el oxígeno equivalente de sustancias orgánicas en una muestra acuosa que es susceptible a la oxidación por dicromato de potasio en una solución de ácido sulfúrico del agua residuales, sus características y la forma en que se tomaron las muestras (8).

Bacterias. Pueden ser autótrofas o heterótrofas. En procesos de lodos activos normalmente las bacterias constituyen el $95 \%$ del material celular (biomasa). La temperatura del medio es importante para el crecimiento bacteriano y de otros organismos, cada especie de bacterias se desempeña mejor dentro de cierto rango de temperatura, fuera de estas temperaturas su actividad es afectada apreciablemente, como se muestra en la Tabla 1.

Tabla 1. Clasificación de bacterias según el rango de temperatura (9).

\begin{tabular}{ccc}
\hline Clasificación & Rango de Temperatura, ${ }^{\circ} \mathbf{C}$ & Optimo, ${ }^{\circ} \mathbf{C}$ \\
\hline Psicrofilas & -5 a 30 & 10 a 20 \\
Mesófilas & 10 a 45 & 20 a 40 \\
Termófilas & 50 a 60 & 25 a 80 \\
\hline
\end{tabular}

\section{Aguas Residuales}

Son cualquier tipo de agua cuya calidad se vio afectada negativamente por influencia antropogénica. Las aguas residuales que se aprovechan para el riego de áreas verdes; generalmente provienen de residencias, instituciones públicas o privadas, establecimientos comerciales e industriales, o la mezcla de todas ellas. Estas aguas contienen cierta cantidad de nutrientes, sin embargo, al 
no ser tratadas presentan un peligro para el medio ambiente y la salud del hombre. Según Montoya (10), las aguas residuales presentan algunos elementos que limitan su uso en riego.

El objetivo de la investigación fue evaluar el tratamiento de aguas residuales domesticas mediante reactor anaerobio y su influencia significativa en la reutilización del efluente en cultivos agrícolas, como consecuencia del estudio de investigación, en base monitoreo realizado in situ en las fechas programadas con el permiso de la Municipalidad de Ica (11). La investigación tiene como aporte el desarrollo tecnológico del distrito de Ica, en el mejor y efectivo tratamiento de las aguas residuales domesticas de la zona. Asimismo, la reducción de contaminantes de las aguas residuales para que éstas puedan ser reutilizadas en la mejora del medio ambiente, como en los cultivos agrícolas.

\section{MATERIALES Y MÉTODOS}

República del Perú, está ubicado en el centro oeste del país, limitando al norte con Lima, al este con Huancavelica y Ayacucho, al sur con Arequipa y al oeste con el Océano Pacifico. Según INEI (12) , con $2132783 \mathrm{~km}^{2}$ es el sexto departamento menos extenso y se fundó el 30 de enero de 1866, su territorio es casi por completo parte del desierto costero del Perú y conforma el llamado gran tablazo de Ica, con sus cinco provincias y es como sigue: Chincha, Pisco, Ica, Palpa y Nasca.

\section{Puntos de monitoreo}

Se establecieron dos puntos de monitoreo en el tratamiento de aguas domesticas mediante reactor anaerobio con fines de reutilización del efluente en cultivos agrícolas, con las siguientes coordenadas UTM. El punto ARD-010 (8 $438872 \mathrm{~N}$ - 421 590E) y el punto ARD-020 (8 439156N-421 346E), (Coordenadas UTM: Datum WGS84 Huso 18 Sur), la altitud media a 150 m.s.n.m. en la siguiente imagen.

\section{Área de estudio}

El departamento de Ica es uno de los veinticuatro departamentos que forman la

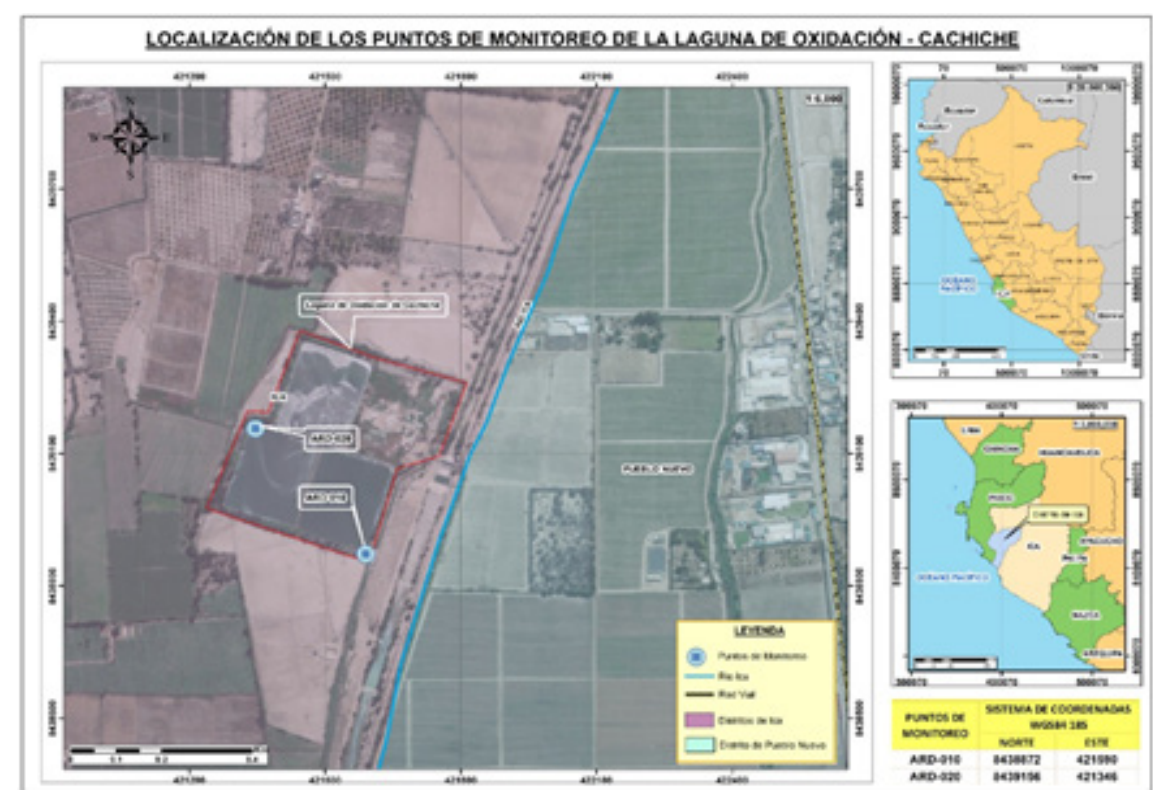

Figura 1. Localización de los puntos de monitoreo de la Laguna de Oxidación-Cachiche: Puntos para el monitoreo: ARD-010 y ARD-020. 


\section{La investigación}

Se realizó dos pruebas en la laguna de oxidación-Cachiche, ubicado en el Distrito de Ica, Provincia de Ica, Región de Ica, la investigación realizada fue de tipo experimental, de nivel descriptivo-explicativo, diseño experimental.

En la investigación experimental se consideró las siguientes fases para el sistema de tratamiento de las aguas residuales domésticas y caracterización inicial de las aguas residuales, como la caracterización a la salida del agua residual en el reactor. En el análisis del proceso se pueden emplea para el tratamiento del agua residual lo siguiente: Desarrollo experimental (Tratamiento Biológico); Caracterización final del efluente luego del tratamiento; y Evaluación de los resultados.

\section{Enfoque cuantitativo}

Se realizó el tratamiento del agua residual procedente de la laguna de oxidaciónCachiche, en un reactor biológico continuo a escala de laboratorio, durante el tratamiento se tomará muestra representativa a la salida del reactor biológico para medir la concentración de sólidos suspendidos volátiles en el licor de mezcla, SS, DQO, $\mathrm{DBO}_{5}, \mathrm{CT}, \mathrm{CF}, \mathrm{pH}$ y el Oxígeno disuelto.

\section{Parámetros utilizados}

$\mathrm{pH}=$ Potencial de Hidrógeno

DQO = Demanda Química de Oxígeno

$\mathrm{DBO}_{5}=$ Demanda Biológica de Oxígeno

SS = Sólidos Suspendidos T = Temperatura

$\mathrm{CT}=$ Coliformes Totales

$\mathrm{CF}=$ Coliformes Fecales

OD = Oxígeno Disuelto

\section{Observaciones e instrumentos}

En el cercado de la provincia de Pisco, se localizaron los puntos: ARD-010 y ARD-020, se realizó el monitoreo in situ en las fechas coordinadas con la Municipalidad de Ica: 06 de febrero y 02 de abril del 2021 respectivamente, en los dos puntos seleccionados como se observa en la Figura 1, pruebas realizadas in situ, se accedió a los análisis respectivos para obtener los parámetros del estudio de investigación como se detallan en la Tabla 2.

Tabla 2. Estaciones de Muestreo de la Laguna de Oxidación-Cachiche.

\begin{tabular}{cccccccccc}
\hline Origen & Puntos & Descripción & Localidad & Distrito & Provincia & Departamento & \multicolumn{2}{c}{ Coordenadas UTM } \\
\cline { 5 - 8 } $\begin{array}{c}\text { Aguas } \\
\text { residuales } \\
\text { domesticas }\end{array}$ & ARD & $\begin{array}{c}\text { Ingreso del } \\
\text { Afluente PTARD } \\
\text { Cachiche }\end{array}$ & $\begin{array}{c}\text { Caserín } \\
\text { Aguas }\end{array}$ & Cachiche & Ica & Ica & Ica & 421590 & 8438872 \\
$\begin{array}{c}\text { residuales } \\
\text { domesticas }\end{array}$ & ARD & $\begin{array}{c}\text { Salida del } \\
\text { Efluente PTARD } \\
\text { Cachiche }\end{array}$ & $\begin{array}{c}\text { Caserín } \\
\text { Cachiche }\end{array}$ & Ica & Ica & Ica & 421346 & 8439156 \\
\hline
\end{tabular}


Se realizó el monitoreo in situ, siguiendo los criterios establecidos en el protocolo de monitoreo de efluentes líquidos y emisiones atmosféricas, aprobado por Resolucion Ministerial N²73-2013-VIVIENDA (13), l Protocolo de Monitoreo de la Calidad de los Efluentes de las Plantas de Tratamiento de Aguas Residuales Domésticas o Municipales PTAR protocolo de vigilancia de los recursos hídricos (14), el reglamento de estándares nacionales de calidad de agua $(15,16)$, decreta en su artículo $1^{\circ}$ Aprobación de Límites Máximos Permisibles (LMP) para efluentes de Plantas de Tratamiento de Aguas Residuales Domésticas o Municipales (PTAR), aprobar los
Límites Máximos Permisibles para efluentes de las Plantas de Tratamiento de Aguas Residuales Domésticas o Municipales, Tabla 3.

Se utilizó un GPS (Garmin ETREX) para georreferenciar la zona, para levantar información de las coordenadas UTM, sistema: WGS-84, Zona: 18L para la ubicación geográfica de los puntos, además se utilizó un medidor de $\mathrm{pH}$ digital marca OAKTON, Modelo pH 310 para la determinación del potencial de hidrogeno para la determinación de los parámetros químicos de interés, se empleó un equipo MULTIPARAMETRO HACH modelo HQ40d, para la Medición in situ de T, pH, OD y CE.

Tabla 3. Límites Máximos Permisibles para efluentes de PTARD: D.S. Nº03-2010-MINAM.

\begin{tabular}{ccccccccc}
\hline PARÁMETRO & pH & DQO & $\mathbf{T}^{\circ} \mathbf{C}$ & DBO & TDS & $\begin{array}{c}\text { COLIFORMES } \\
\text { TERMOTOLERANTES } \\
\text { NMP/100 } \mathbf{~ m l}\end{array}$ & $\begin{array}{c}\text { COLIFORMES } \\
\text { FECALES } \\
\text { NMP/100 ml }\end{array}$ & A\&G \\
\hline $\begin{array}{c}\text { D.S. N } \text { N }^{\circ} \text { 003-2010- } \\
\text { MINAM LMP } \\
\text { Aguas Residuales }\end{array}$ & $6.5-8.5$ & 200 & $<35$ & 100 & 150 & 10,000 & $\ldots$ & 20 \\
\hline
\end{tabular}

\section{Desarrollo experimental}

La parte experimental de esta investigación se realizó en un reactor biológico continuo, a escala de laboratorio en la Facultad de Ingeniería Ambiental y Sanitaria, Universidad Nacional San Luis Gonzaga-Ica. El afluente a tratar "Agua Residual" domestica del colector de la Laguna de oxidación-Cachiche, Distrito de Ica, la toma de muestra se realizó al ingreso a la laguna de oxidación, como se observa en la imagen. 

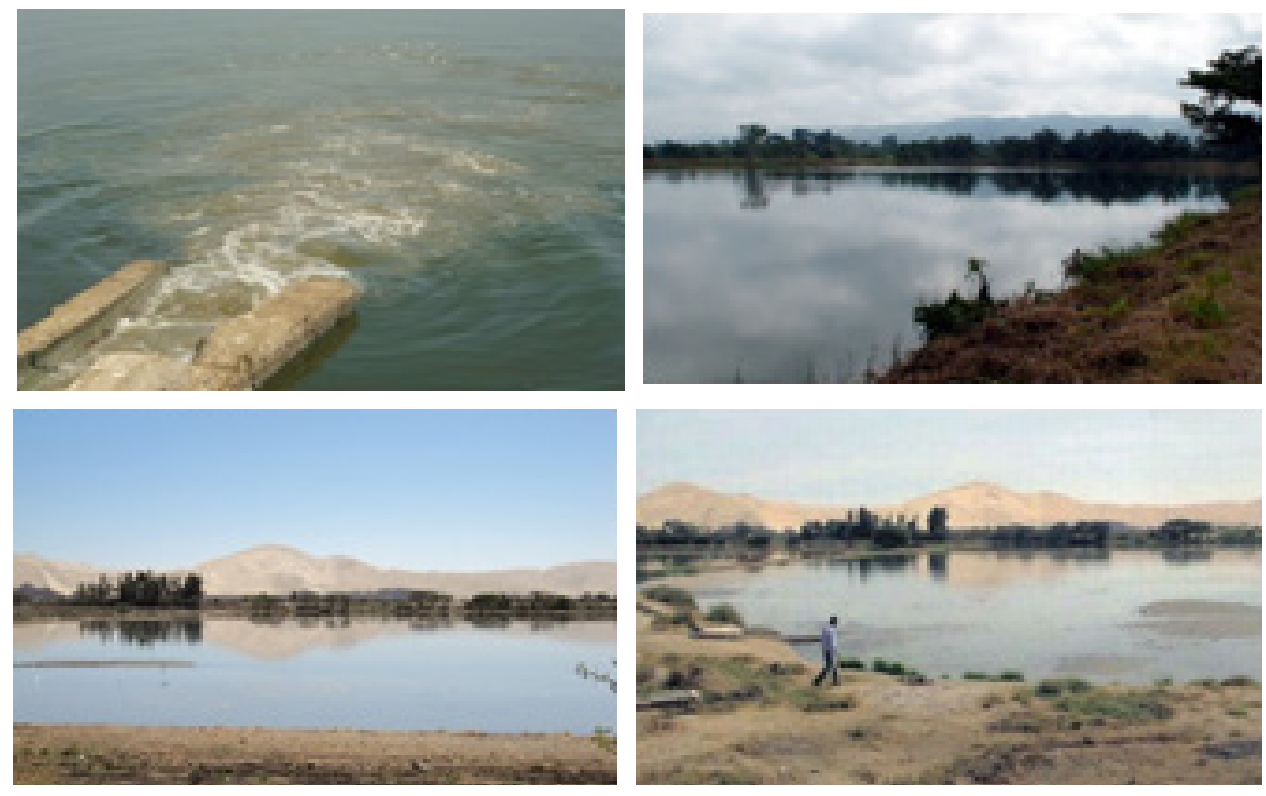

Figura 2. Laguna de Oxidación-Cachiche, Distrito de Ica.

Elreactorfuehechodeacrílicotransparente, como se muestra en la imagen. La capacidad de la cámara de aireación y sedimentación es de 8 litros respectivamente. El lodo fue obtenido de la planta de tratamiento de YaurillaParcona, ubicado en la provincia de la Ica, esto con la finalidad de que se adapten mejor y en el menor tiempo posible para biodegradar la materia orgánica del agua residual doméstica. El lodo obtenido se conservó a $10^{\circ} \mathrm{C}$ hasta su adaptación, la biomasa se le alimento agua residual de la laguna de oxidación-Cachiche en el reactor por 17 días a un flujo constante y a temperatura ambiente, luego se colocó el reactor en un sistema de calefacción a una temperatura de $34^{\circ} \mathrm{C}$ por 78 días, aun $\mathrm{pH}$ es constante, para obtener el lodo anaerobio.

\section{Procedimiento}

Para el tratamiento del afluente se considera las siguientes etapas:

- Toma de la muestra "agua residual al ingreso de la laguna de oxidación.

- Toma de la muestra de la biodegradación de la materia orgánica a las 32 horas.

- Toma de la muestra "agua residual a la salida del reactor. 


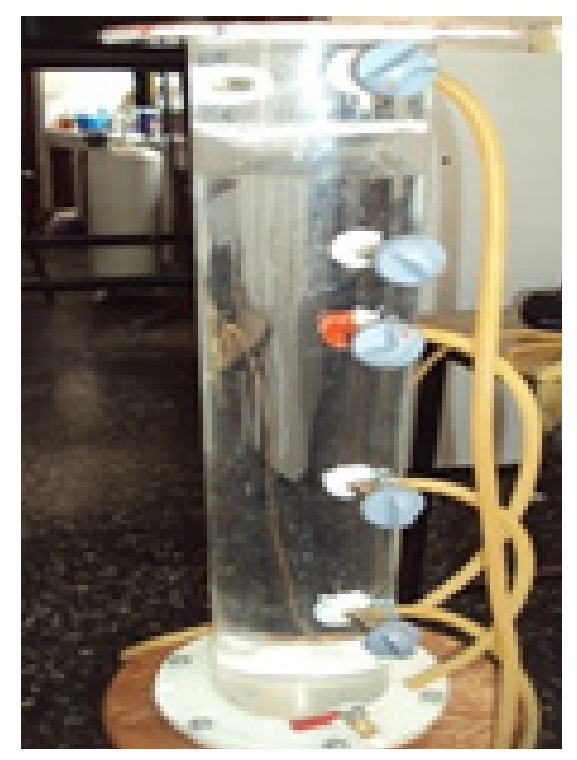

Figura 3. Reactor de flujo continuo a escala de laboratorio.

\section{Toma de la muestra "agua residual"}

La muestra de agua residual fue extraída al ingreso y salida de la PTARD Cachiche, Distrito de Ica, ver imagen.
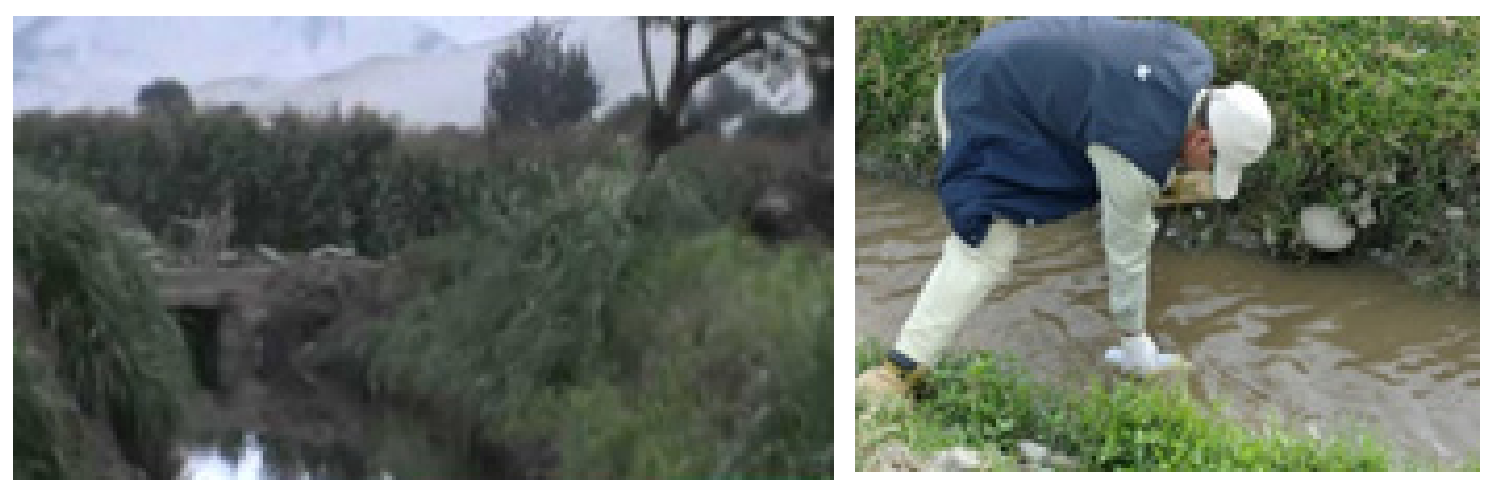

Figura 4. Laguna de Oxidación que se encuentra ubicada en Cachiche-Ica.

Caracterización del afluente (Agua residual cruda)

Caracterización del agua residual en la alimentación del reactor, se tomó la muestra de la Laguna de Oxidación-Cachiche, Distrito de Ica, como se muestra en la Tabla 4, durante el mes de febrero. Se adiciona cal para ajustar el pH del agua residual según las necesidades de la misma, para operar en un rango de $\mathrm{pH}$ entre 6 y 8. 
Tabla 4. Resultados de caracterización del ARD de la Laguna de Oxidación-Cachiche.

\begin{tabular}{|c|c|c|c|c|c|c|}
\hline \multirow{4}{*}{ Parámetros } & \multirow{4}{*}{ Unidad } & \multirow{4}{*}{ LMP } & \multicolumn{2}{|c|}{ Afluente } & \multicolumn{2}{|c|}{ Efluente } \\
\hline & & & ARD-010-A & ARD-010-B & ARD-020A & ARD-020-B \\
\hline & & & 06.02 .2021 & 02.04 .2021 & 06.02 .2021 & 02.04 .2021 \\
\hline & & & Hora: 8:00 am & Hora: 10:00 am & Hora: 8:00 am & Hora: 10:00 am \\
\hline Aceites y Grasas & $\mathrm{mg} / \mathrm{L}$ & 20 & 62 & 66 & 35 & 26 \\
\hline Coliformes Totales & $\mathrm{NMP} / 100 \mathrm{ml}$ & 10000 & 18000000 & 9200000 & $47 \times 105$ & $11 \times 106$ \\
\hline $\begin{array}{l}\text { Coliformes } \\
\text { Termotolerantes }\end{array}$ & $\mathrm{NMP} / 100 \mathrm{ml}$ & $N, D$, & 3200000 & 3500000 & $39 \times 105$ & $7 \times 106$ \\
\hline $\mathrm{DBO} 5$ & $\mathrm{mg} / \mathrm{L}$ & 100 & 320 & 297 & 216 & 190 \\
\hline DQO & $\mathrm{mg} / \mathrm{L}$ & 200 & 345 & 360 & 236 & 242 \\
\hline $\mathrm{pH}$ & Unidad de $\mathrm{pH}$ & $6.5-8.5$ & 7.8 & 7,85 & 7,9 & 7,8 \\
\hline $\begin{array}{l}\text { Solidos Totales } \\
\text { Suspendidos }\end{array}$ & $\mathrm{mg} / \mathrm{L}$ & 150 & 335 & 290 & 180 & 186 \\
\hline Temperatura & ${ }^{\circ} \mathrm{C}$ & $<35$ & 21 & 26 & 25 & 26 \\
\hline
\end{tabular}

RESULTADOS Y DISCUSIÓN

Después del periodo de adaptación de la biomasa anaerobia, se analizó el afluente ARD-010, en las fechas indicadas, Tabla 4, y luego se analizó el efluente para determinar la biodegradación de la materia orgánica, que se realizó en el reactor anaerobio, considerándose las coordenada UTM, Figura 1, para la laguna de oxidación de Cachiche con los puntos ARD010-A como afluente, se realizó el recojo de muestra a horas 8:00 am., luego se alimentó al reactor anaerobio, se tomaron varias muestras $\mathrm{TR}-\mathrm{H}$ del sistema de tratamiento de aguas residuales hasta un TR-32 horas, iniciándose el (06.02.2021), Tabla 5. Para el ARD-010-B como afluente se alimentó al reactor a hora 10:00 am, luego se alimentó al reactor anaerobio, se tomaron varias muestras $\mathrm{TR}-\mathrm{H}$ del sistema de tratamiento de aguas residuales hasta un TR32 horas, iniciándose el (02.04.2021), Tabla 6. Se muestra la Tabla 7 de los coliformes totales a $35^{\circ} \mathrm{C}$ y coliformes fecales a $44.5^{\circ} \mathrm{C}$. 
Tabla 5. Datos de las pruebas realizadas el 06 de febrero del 2021.

\begin{tabular}{lcccccccc}
\hline Parámetros & Unidad & TR-8 & TR-12 & TR-16 & TR-20 & TR-24 & TR-28 & TR-32 \\
\hline Aceites y Grasas & $\mathbf{m g} / \mathbf{L}$ & 27.8 & 18.0 & 3.8 & 2.0 & 1.1 & 0.7 & 0.6 \\
Coliformes Termotolerantes & $\mathbf{N M P / 1 0 0 m L}$ & 2800000 & 640000 & 260000 & 26000 & 8000 & 1800 & 890 \\
DB05 & $\mathbf{m g} / \mathbf{L}$ & 225 & 162 & 133 & 68 & 26 & 14 & 8 \\
DQ0 & $\mathbf{m g} / \mathbf{L}$ & 261 & 176 & 138 & 78 & 38 & 32 & 27 \\
pH & Unidad de $\mathbf{~ H H}$ & 7.80 & 7.60 & 7.50 & 7.70 & 7.70 & 7.70 & 7.60 \\
TSS & $\mathbf{m g} / \mathbf{L}$ & 335 & 224 & 182 & 100 & 48 & 46 & 38 \\
Temperatura & ${ }^{\circ} \mathbf{C}$ & 32.60 & 33.00 & 33.20 & 32.600 & 33.20 & 33.50 & 33.00 \\
\hline
\end{tabular}

Tabla 6. Datos de las pruebas realizadas el 02 de abril de 2021.

\begin{tabular}{lcccccccc}
\hline Parámetros & Unidad & TR-8 & TR-12 & TR-16 & TR-20 & TR-24 & TR-28 & TR-32 \\
\hline Aceites y Grasas & $\mathbf{m g} / \mathbf{L}$ & 28 & 19.0 & 4.8 & 2.2 & 1.3 & 0.6 & 0.5 \\
Coliformes Termotolerantes & $\mathbf{N M P / 1 0 0 m l}$ & 2600000 & 650000 & 250000 & 22000 & 8000 & 1600 & 920 \\
DBO5 & $\mathbf{m g} / \mathbf{L}$ & 252 & 176 & 120 & 65 & 22 & 15 & 10 \\
DQO & $\mathbf{m g} / \mathbf{L}$ & 241 & 189 & 160 & 92 & 45 & 38 & 26 \\
pH & Unidad de $\mathbf{~ p H}$ & 7.80 & 7.70 & 7.60 & 7.60 & 7.70 & 7.70 & 7.60 \\
TSS & $\mathbf{m g} / \mathbf{L}$ & 335 & 222 & 181 & 98 & 46 & 42 & 36 \\
Temperatura & ${ }^{\circ} \mathbf{C}$ & 32.00 & 33.00 & 33.50 & 32.50 & 33.40 & 33.00 & 33.00 \\
\hline
\end{tabular}

Tabla 7. Resultados de Ensayos Microbiológicos del Agua Residual Domestica de la Laguna de Oxidación-Cachiche, Distrito de Ica.

(06 de febrero del 2021)

\begin{tabular}{|c|c|c|c|c|}
\hline \multirow{2}{*}{$\begin{array}{l}\text { Código } \\
\text { Laboratorio }\end{array}$} & \multicolumn{2}{|c|}{ Muestra } & \multicolumn{2}{|c|}{ Ensayos } \\
\hline & Tipo & Punto de Muestreo & $\begin{array}{l}\text { Coliformes Totales } \\
35^{\circ} \mathrm{C} \text { (NMP/100ml) }\end{array}$ & $\begin{array}{l}\text { Coliformes Fecales } \\
44.5^{\circ} \mathrm{C}(\mathrm{NMP} / 100 \mathrm{ml})\end{array}$ \\
\hline ARD-010 & $\begin{array}{l}\text { Muestra de } \\
\text { agua residuales } \\
\text { domesticas }\end{array}$ & $\begin{array}{l}\text { Ingreso del Afluente } \\
\text { a la PTAR - Cachiche }\end{array}$ & $92 \times 10^{5}$ & $35 \times 10^{5}$ \\
\hline ARD-020 & $\begin{array}{l}\text { Muestra de } \\
\text { agua residuales } \\
\text { domesticas }\end{array}$ & $\begin{array}{c}\text { Salida del efluente } \\
\text { de la PTAR - } \\
\text { Cachiche }\end{array}$ & $47 \times 10^{5}$ & $3,9 \times 10^{5}$ \\
\hline
\end{tabular}


(02 de abril del 2021)

\begin{tabular}{|c|c|c|c|c|}
\hline \multirow{2}{*}{$\begin{array}{c}\text { Código } \\
\text { Laboratorio }\end{array}$} & \multicolumn{2}{|c|}{ Muestra } & \multicolumn{2}{|c|}{ Ensayos } \\
\hline & Tipo & Punto de Muestreo & $\begin{array}{l}\text { Coliformes Totales } \\
35^{\circ} \mathrm{C} \text { (NMP/100ml) }\end{array}$ & $\begin{array}{l}\text { Coliformes Fecales } \\
44.5^{\circ} \mathrm{C}(\mathrm{NMP} / 100 \mathrm{ml})\end{array}$ \\
\hline ARD-010 & Muestra de Agua & Ingreso Laguna & $18 \times 10^{6}$ & $32 \times 10^{5}$ \\
\hline ARD-020 & Muestra de Agua & Salida Laguna & $11 \times 10^{6}$ & $7 \times 10^{5}$ \\
\hline
\end{tabular}

Resultados de los datos obtenidos el día 06 de febrero del 2021: DBO (5)

El afluente a tratar en el reactor se tomó a las 8:00 a.m., en el colector de ingreso a la Laguna de Oxidación-Cachiche del Distrito de Ica, al cual se le realizo su respectivo análisis, del agua residual cruda resultado de $320 \mathrm{mg}$ DBO5/l, como se observa en la Tabla 4 y luego llevo al sistema reactor anaerobio, se obtuvo los resultados a diferente TR- $\mathrm{H}$, se muestran en la Tabla 5 y a las de 32 horas se tomó la última muestra del agua residual con el inoculo resultando un TR-32 de $8 \mathrm{mg}$ DBO5/L. En la Tabla 5 , se puede distinguir que la concentración de DBO5 disminuye rápidamente siguiendo una pendiente negativa en las primeras horas, obteniendo una eficiencia del $81.94 \%$.

\section{Resultados de los datos obtenidos el día 06 de febrero del 3021: DQO}

El afluente a tratar en el reactor se tomó a las 8:00 a.m., en el colector de la Laguna de Oxidación-Cachiche del Distrito de Ica, el cual se le realizo su respectivo análisis, del agua residual cruda resultado de $345 \mathrm{mg}$ DQO/l, como se observa en la Tabla 4 y luego llevo al sistema reactor de flujo ascendente, obteniéndose los resultados a diferente TR-H, se muestran en la Tabla 5 y a las de 32 horas se tomó la última muestra del agua residual con el inoculo resultando un TR-32 de $27 \mathrm{mg}$ DQO/L. En la Tabla 5, se puede distinguir que la concentración de DQO disminuye más en las primeras horas, obteniendo una eficiencia del $80.17 \%$.

\section{Resultados de los datos obtenidos el día 02 de abril del 2021: DBO (5)}

El afluente a tratar en el reactor se tomó a las 10:00 a.m., en el colector de ingreso a la Laguna de Oxidación-Cachiche del Distrito de Ica, al cual se le realizo su respectivo análisis, del agua residual cruda resultado de 297 mg DBO5/L, como se observa en la Tabla 4 y luego llevo al sistema reactor anaerobio, se obtuvo los resultados a diferente TR-H, se muestran en la Tabla 6 y a las de 32 horas se tomó la última muestra del agua residual con el inoculo resultando un TR-32 de $10 \mathrm{mg}$ DBO5/L. En la Tabla 6, se puede distinguir que la concentración de DBO5 disminuye más en las primeras horas, obteniendo una eficiencia del $79.11 \%$. 


\section{Resultados de los datos obtenidos el día 02 de abril del 2021: DQO}

El afluente a tratar en el reactor se tomó a las 10:00 a.m., en el colector de la Laguna de Oxidación-Cachiche del Distrito de Ica, el cual se le realizo su respectivo análisis, del agua residual cruda resultado de $360 \mathrm{mg}$ DQO/L, como se observa en la Tabla 4 y luego llevo al sistema reactor de flujo ascendente, obteniéndose los resultados a diferente TR- $\mathrm{H}$, se muestran en la Tabla 6 y a las de 32 horas se tomó la última muestra del agua residual con el inoculo resultando un TR-32 de $26 \mathrm{mg}$ DQO/L. En la Tabla 6, se puede distinguir que la concentración de DQO disminuye más en las primeras horas, obteniendo una eficiencia del $77.30 \%$.

\section{CONCLUSIONES}

El reactor biológico se le adiciono el $23 \%$ del volumen total, equivalente a $1130.4 \mathrm{ml}$, el resto fue agua residual haciendo un total de $5000 \mathrm{ml}$., se dejó por 14 días y el reactor estuvo a una temperatura ambiente. Luego el sistema listo para la biodegradación de la materia orgánica de la DB05 a 32 Horas con una eficiencia del $81.94 \%$, para la DBO5 (06.02.2021) y a las 32 Horas con una eficiencia del $79.11 \%$, para la DBO5 (02.04.2021).

El tratamiento con reactor anaerobio y la reutilización de aguas residuales domesticas para cultivos agrícolas se obtuvieron para TR32 horas con pH de 7.7; solidos suspendidos 38 $\mathrm{mg} / \mathrm{l}$ y para los coliformes termo tolerantes un valor $890 \mathrm{NMP} / 100 \mathrm{ml}$; valores que se encuentran por debajo de los estándares de calidad ambiental ECA AGUA para su reusó en la Categoría 3: Riego de vegetales y bebida de animales del DECRETO SUPREMO $\mathrm{N}^{\circ}$ 004-2017-MINAM.

En referencia a los parámetros microbiológicos que indican la contaminación por patógenos existe una gran diferencia en la eficiencia del modelo anaeróbico respecto al de la PTARD cuyos resultados son de $890 \mathrm{NMP} / 100 \mathrm{ml}$ y $700000 \mathrm{NMP} / 100 \mathrm{ml}$ respectivamente.

\section{REFERENCIAS BIBLIOGRÁFICAS}

1. Azimi AA, Zamanzadeh M. Determination of Design Criteria for UASB Reactors as a Wastewater Pretreatment System in Tropical Small Communities. Int J Environ Sci Tech. 2004;1(1):121-129. http://applications.emro. who.int/imemrf/Int_J_Environ_Sci_Technol/ Int_J_Environ_Sci_Technol_2004_1_1_51_57. pdf

2. Banu JR, Kaliappan S, Yeom IT. Treatment of Domestic Wastewater Using Upflow Anaerobic Sludge Blanket Reactor. Int J Environ Sci Technol. 2007;4:363-370 p. doi:https://doi. org/10.1007/BF03326295

3. Bellido S, Estrella M. Puesta en marcha de un reactor biologico discontinuo con una biomasa anaerobia y un sustrato de lixiviado. Published online 2003.

4. García C. Agua dulce y agua salada.

5. Vasquez A, Valdez E. Ingenieria de los sistemas de tratamiento y disposicion de aguas residuales tratamiento de agua. Fundacion ICA mexico; 2003.

6. Setty AKE, Kayser $G L$, Bowling $M$, et al. Water quality, compliance, and health outcomes among utilities implementing Water Safety Plans in France and Spain. Int J Hyg Environ Health. Published online 2017;43 pp. doi:10.1016/j.ijheh.2017.02.004

7. Ferrer J, Seco A. Tratamientos biologicos de aguas residuales. Primera Ed. Alfa Omega Grupo Editor; 2008. 
8. Ramirez L, Duran M. Demanda quimica de oxigeno de muestras acuosas. Serie: Quimica Ambiental de los Residuos Peligrosos. Volumen 1. Programa de Ingeniería Química Ambiental y de Química Ambiental (PIQAyQA) Facultad de Química, Universidad Nacional Autónoma de México; 2008.

9. Shomar B, Al-Darwish K, Vincent A. Optimization of wastewater treatment processes using molecular bacteriology. J Water Process Eng. 2020;33(August 2019):101030. doi:10.1016/j.jwpe.2019.101030

10. Montoya E. Evaluación de alternativas para la instalación de un Sistema de Tratamiento de Aguas Residuales con fines de riego agrícola en el sub sector San Agustín - Callao (Perú). Published online 2007.

11. Ayesa Iturrate E, Larrea Urcola MA. Optimización del diseño, operación y control de las EDAR utilizando modelos matemáticos y herramientas de simulación. Tecnol del Agua. 2005;25(266):74-79.

12. INEI. INSTITUTONACIONALDEESTADÍSTICA E INFORMÁTICA. 2017. https://www.inei.gob. pe/media/MenuRecursivo/publicaciones digitales/Est/Lib1496/libro.pdf

13. Resolucion Ministerial $\mathrm{N}^{\circ} 026-2000-\mathrm{ITINCl}-$ DM. Resolucion Ministerial N026-2000-ITINCIDM. Published online 2002; p38 . https://www. legislacionambientalspda.org.pe/images/ stories/normas/Pioner 2/IV. 4. Industrial/4. Resoluciones ministeriales/Resolucion ministerial 026-2000-ITINCI-DM.doc

14. DIGESA_007_VI. Procedimientos Para la Vigilancia de los Recursos HidricosICOS - Seguimiento de la(s) Muestra(s) -. Published online 2002;6 pag. https://www. legislacionambientalspda.org.pe/images/ stories/normas/Pioner 2/IV. 4. Industrial/4. Resoluciones ministeriales/Resolucion ministerial 026-2000-ITINCI-DM.doc

15. Decreto Supremo $N^{\circ} 004-2017-M I N A N$. Aprueban Estándares de Calidad Ambiental (ECA) para Agua y Establecen Disposiciones Complementarias. El Peruano. http://www. minam.gob.pe/wp-content/uploads/2017/06/ DS-004-2017-MINAM.pdf. Published 2017.

16. Decreto Supremo N003-MINAM (Ministerio del Ambiente). Aprueban Limites Máximos Permisibles para los efluentes de Plantas de Tratamiento de Aguas Residuales Domésticas o Municipales. Normas Leg El Peru. Published online 2010:1-2. http://www.minam.gob.pe/ wp-content/uploads/2013/09/ds_003-2010minam.pdf 